\title{
AÇÃO DO HERBICIDA TRIFLURALIN NA GERMINAÇÃO E NO DESENVOLVIMENTO INICIAL DE MILHO, SORGO E MILHETO
}

\author{
Lorenzon $\mathrm{J}^{*}$, Yamashita $\mathrm{OM}^{* *}$, Panosso $\mathrm{A}^{* * *}$, Franceschi $\mathrm{M}^{* * *}$, Campos $\mathrm{OR}^{* * * * *}$
}

Resumo

O uso inadequado de doses de herbicidas pode contribuir para que resíduos permaneçam no solo e influenciem a germinação e a emergência de culturas. No presente trabalho teve-se como objetivo avaliar a germinação e o desenvolvimento de plântulas (milho, milheto e sorgo) quando em contato com o herbicida trifluralin. A pesquisa foi organizada em delineamento inteiramente casualizado em esquema fatorial 3x4, sendo três espécies (milho, sorgo, milheto) e quatro doses (testemunha (água destilada), 1/4, 1/2 e 1x a dose recomendada do herbicida trifluralin), sendo cada uma repetida quatro vezes. Cada repetição foi composta por 50 sementes. Foram avaliados os seguintes parâmetros: teste padrão de germinação, Índice de Velocidade de Germinação (IVG), crescimento de plântulas (comprimento da maior raiz, parte aérea, número de ramificações) e peso seco de plântulas. As médias dos resultados foram submetidas à análise de variância, e, para as causas de variações significativas, foi utilizado o teste Tukey a 5\% de probabilidade. A espécie milho foi considerada a mais tolerante aos efeitos do herbicida quando em contato. O produto utilizado, mesmo em sua menor dose, causou fitotoxidade nas espécies estudadas, principalmente no desenvolvimento radicular. $\mathrm{O}$ milheto foi a cultura mais sensível ao herbicida.

Palavras-chave: Pesticidas. Fitointoxicação. Pré-emergência. Dinitroanilina.

\footnotetext{
* Graduando em Agronomia pela Universidade do Estado de Mato Grosso de Alta Floresta; juliano-lorenzon@outlook.com

** Doutor e Mestre em Agricultura Tropical pela Universidade Federal de Mato Grosso; Professor da Universidade do Estado de Mato Grosso; Avenida Perimetral Rogério Silva, 4390, Jardim Flamboyant, 78580-000, Alta Floresta, Mato Grosso, Brasil; yama@unemat.br

${ }^{* * *}$ Graduando em Agronomia pela Universidade do Estado de Mato Grosso de Alta Floresta; arthur_panosso62@hotmail.com

${ }^{* * * *}$ Mestre em Agronomia pela Universidade Federal de Mato Grosso; mauriciofranceschi123@hotmail.com

${ }^{* * * * *}$ Doutor e Mestre em Agronomia (Proteção de Plantas) pela Universidade Estadual Paulista Júlio de Mesquita Filho; Professor na Universidade do Estado de Mato Grosso; campos@unemat.br
} 


\title{
Trifluralin action on seeds germination and initial development of corn, sorghum and millet
}

\author{
Abstract
}

Improper use of herbicides doses may contribute to residue remains on the ground and influence the germination and emergence of crops. In this study it was aimed to evaluate the germination and seedling development (corn, millet and sorghum) when in contact with the herbicide trifluralin. The research was organized in a completely randomized design in a $3 \times 4$ factorial design, with three species (corn, sorghum, millet) and four doses (control (distilled water), 1/4,1/2 and $1 x$ the recommended dose of the herbicide trifluralin), and each one was repeated four times. Each repetition consisted of 50 seeds. The following parameters were evaluated: standard germination test, Speed of Germination Index (SGI), seedling growth (highest root length, shoot, number of branches) and dry weight of seedlings. The average values of the results were submitted to analysis of variance, and to the significant variations, the Tukey test at $5 \%$ probability was used. The corn species was considered the most tolerant to the effects of herbicide when in contact. The product used, even in its lowest dose, caused phytotoxicity on the studied species, especially in root development. The millet was the most sensitive crop to the herbicide.

Keywords: Pesticides. Phytotoxicity. Pre-emergence. Dinitroanilines.

\section{INTRODUÇÃO}

A utilização de herbicidas em pré-emergência é uma prática comum em diversas culturas, como arroz, milho e algodão. Tem como finalidade o controle de plantas daninhas na germinação e/ ou na emergência e, também, em sua atividade residual; mantém a lavoura "no limpo" no início do ciclo das culturas, reduzindo novos fluxos de plantas daninhas. Assim, é possível que a cultura possa emergir, evitando-se a interferência, até que outra prática de manejo seja adotada. ${ }^{1}$

Entretanto, dependendo das propriedades físico-químicas do herbicida, da dose utilizada e das condições edafoclimáticas da região, esses produtos podem permanecer no solo, afetando o desenvolvimento das culturas subsequentes, como soja e feijão. ${ }^{2}$

O trifluralin é um herbicida intensamente utilizado no controle de plantas daninhas em diversas culturas no Centro-Sul do Brasil, sendo aplicado diretamente no solo, em pré-emergência ou pré-plantio incorporado. ${ }^{3}$ Pertence ao grupo químico das dinitroanilinas e apresenta baixa solubilidade. É pouco lixiviável, e sua volatilização e degradação aumentam com a elevação da temperatura e da umidade do solo. ${ }^{4}$

Embora seja considerado relativamente não persistente no solo, verifica-se a atividade desse herbicida por períodos mais prolongados do que o esperado, principalmente em áreas de clima temperado. ${ }^{5}$ Os principais fatores que contribuem para a degradação do trifluralin quando aplicado no solo são a fotólise, a volatilização e a decomposição microbiana. ${ }^{6}$ Assim, dependendo da condição, 
podem permanecer no solo, em concentrações que podem provocar prejuízos e até a morte de plantas nos cultivos subsequentes, ocasionando o carryover, ou seja, o efeito residual no solo.

O milho é uma das culturas anuais de maior importância econômica para o Brasil, pois possui grande potencial na geração de renda. Seu cultivo é realizado, principalmente, após a safra principal, e, com o sorgo e o milheto, compõe as principais espécies de exploração econômica em final de safra. ${ }^{7}$

Um dos principais problemas nessas culturas é o manejo de pragas, doenças e, principalmente, de plantas daninhas. Segundo Vargas et al., ${ }^{8}$ a não realização de controle dessas plantas pode gerar perdas de $85 \%$ na produção e até, em alguns casos, haver perda total da produção.

Com o contínuo incremento da área de plantio do chamado "milho safrinha”, após o cultivo de verão, torna-se de grande importância investigar a possibilidade de aparecimento de carry over dos herbicidas aplicados para manejo de plantas daninhas nas culturas antecessoras. ${ }^{6,1}$

No presente trabalho teve-se por objetivo avaliar a germinação e o desenvolvimento inicial de plântulas de milho, milheto e sorgo quando em contato com o herbicida trifluralin em diferentes concentrações.

\section{MATERIAL E MÉTODOS}

O experimento foi conduzido no Laboratório de Tecnologia de Sementes e Matologia (LaSeM) da Universidade do Estado de Mato Grosso Unemat, Campus Universitário de Alta Floresta, no ano 2015.

O trabalho foi instalado no delineamento inteiramente casualizado em esquema fatorial 3x4, sendo três espécies (milho, sorgo, milheto) x quatro doses de trifluralin (testemunha (água destilada), $1 / 4 \mathrm{X} 1 / 2 \mathrm{x}$ e $1 \mathrm{x}$ da dose recomendada para a cultura do milho $\left(3,0 \mathrm{~L} \mathrm{ha}^{-1}\right.$ do produto comercial Trifluralina Nortox), ou seja, $0 ; 0,75 ; 1,50$ e 3,00 L ha-1); cada dose foi repetida quatro vezes. As sementes das espécies foram obtidas com agricultores que as cultivam na região Norte do Estado de Mato Grosso.

Foram confeccionados rolos de papel Germitest, sendo distribuídas 50 sementes em cada repetição de cada tratamento, seguindo umedecimento sugerido por Brasil, ${ }^{9}$ ou seja, aplicação de 2,5 vezes o peso dos papéis para cada rolo confeccionado. Assim, os papéis de cada tratamento foram umedecidos com sua respectiva solução de herbicida. Após esse processo, os rolos foram colocados para germinar em câmara de germinação modelo Mangelsdorf, sendo regulada à temperatura de $25^{\circ} \mathrm{C}$.

As avaliações para obtenção da porcentagem de sementes germinadas foram realizadas diariamente. No $7^{\circ}$ dia, foi realizada a contagem final de sementes germinadas e determinado o comprimento da maior raiz e parte aérea de cada plântula, com auxílio de um paquímetro digital. Logo em seguida, as plântulas foram colocadas em sacos de papel kraft e levadas para estufa de secagem regulada a $65^{\circ} \mathrm{C}$, permanecendo por 72 horas. Após esse período, foram pesadas em balança de precisão para determinação da massa seca média de cada tratamento.

Para efeito de comparação entre as espécies, as variáveis comprimento da parte aérea, comprimento da raiz e massa seca foram convertidas para porcentagem de redução em relação à testemu- 
nha. Para isso, foi realizado o cálculo das proporções de redução em relação à média obtida em cada parcela e, posteriormente, realizada a análise estatística.

As médias dos resultados foram submetidas à análise de variância e, para as causas de variações significativas, foi realizado o teste de Tukey a 5\% de probabilidade, para comparação das médias, utilizando-se o software estatístico Sisvar. ${ }^{10}$

\section{RESULTADOS E DISCUSSÃO}

Os valores médios das variáveis porcentagem de germinação, índice de velocidade de germinação (IVG), comprimento da parte aérea e raiz e massa seca estão apresentados na Tabela 1.

Tabela 1 - Análise de variância de germinação, IVG, comprimento aéreo, comprimento de raiz e massa seca de plântulas de milho, milheto e sorgo cujas sementes foram mantidas para germinar em substrato umedecido com doses crescentes de trifluralin ${ }^{\dagger}$

\begin{tabular}{|c|c|c|c|c|c|}
\hline Espécie (E) & \% Germinação & IVG & $\begin{array}{l}\text { Comprimento } \\
\text { parte aérea }\end{array}$ & $\begin{array}{c}\text { Comprimento } \\
\text { da raiz }\end{array}$ & Massa seca \\
\hline Milho & $97,95 \mathrm{~A}$ & $10,60 \mathrm{~A}$ & $36,47 \mathrm{~A}$ & $34,87 \mathrm{~B}$ & $108,28 \mathrm{~A}$ \\
\hline Milheto & $55,46 \mathrm{C}$ & $5,22 \mathrm{C}$ & $31,00 \mathrm{~A}$ & $31,99 \mathrm{~B}$ & $108,89 \mathrm{~A}$ \\
\hline Sorgo & $72,81 \mathrm{~B}$ & $7,36 \mathrm{~B}$ & $34,90 \mathrm{~A}$ & $44,08 \mathrm{~A}$ & $105,84 \mathrm{~A}$ \\
\hline Valor de F & $135,504^{* *}$ & $117,041^{* *}$ & $2,065 \mathrm{~ns}$ & $16,580^{* *}$ & $0,233 \mathrm{~ns}$ \\
\hline DMS & 6,34 & 0,52 & 6,77 & 5,36 & 11,57 \\
\hline \multicolumn{6}{|l|}{ Doses } \\
\hline 0,00 & $84,34 \mathrm{~A}$ & $9,265 \mathrm{~A}$ & $100,00 \mathrm{~A}$ & $100,00 \mathrm{~A}$ & $100,00 \mathrm{~B}$ \\
\hline 0,75 & $78,51 \mathrm{AB}$ & $8,097 \mathrm{~B}$ & $14,43 \mathrm{~B}$ & $17,45 \mathrm{~B}$ & $104,74 \mathrm{AB}$ \\
\hline 1,50 & $76,14 \mathrm{~B}$ & 7,503 B & $12,80 \mathrm{~B}$ & $17,19 \mathrm{~B}$ & $117,74 \mathrm{~A}$ \\
\hline 3,00 & $62,70 \mathrm{C}$ & $6,049 \mathrm{C}$ & $9,27 \mathrm{~B}$ & $13,28 \mathrm{~B}$ & $108,61 \mathrm{AB}$ \\
\hline Valor de F & $18,734^{* *}$ & $59,348^{* *}$ & $377,674^{* *}$ & $551,824^{* *}$ & $3,603^{* *}$ \\
\hline DMS & 8,07 & 0,66 & 8,64 & 6,82 & 14,72 \\
\hline $\mathrm{E}^{*} \mathrm{C} \quad$ Valor de $\mathrm{F}$ & $4,992^{* *}$ & $12,032^{* *}$ & $0,292 \mathrm{~ns}$ & $2,416^{*}$ & $1,885 \mathrm{~ns}$ \\
\hline CV (\%) & 9,73 & 7,78 & 22,97 & 16,77 & 12,44 \\
\hline
\end{tabular}

Os resultados da interação significativa entre doses e espécies, para a variável porcentagem de germinação de sementes, podem ser verificados na Tabela 2. A germinação do milho foi superior a todas as espécies em todas as concentrações estudadas. Verifica-se que não houve diferença significativa na germinação de sementes de milho, apesar da variação entre 91,5\% na testemunha e 86\% na maior concentração do herbicida. Esse resultado, provavelmente, pode ocorrer em razão da qualidade fisiológica das sementes usadas, sendo que as de milho foram superiores às demais culturas estudadas.

${ }^{\dagger} \mathrm{NS}=$ Não significativo pelo Teste F. ${ }^{*} \mathrm{e}^{* *}=$ Significativo a 1 e $5 \%$ de probabilidade pelo Teste F. Médias seguidas de mesma letra na coluna não diferem entre si pelo teste de Tukey a $5 \%$ de probabilidade. 
Verifica-se, também, que o milho foi a espécie menos sensível à influência do trifluralin na germinação das sementes. Mesmo na maior dose testada, não foi diferente dos resultados obtidos na testemunha, indicando tolerância à dinitroanilina. Resultados semelhantes foram relatados por Santos et al., ${ }^{1}$ que verificaram apenas redução no teor de clorofila de milho tratado com trifluralin.

Tabela 2 - Porcentagem da germinação das sementes de milho, milheto e sorgo submetidas a substrato contaminado com concentrações crescentes de trifluralin $\left(3,0 \mathrm{~L} \mathrm{ha}^{-1}\right)^{\ddagger}$

\begin{tabular}{ccccc}
\hline \multirow{2}{*}{ Espécies } & \multicolumn{4}{c}{ Concentração de trifluralin (x dose recomendada) } \\
\cline { 2 - 5 } & 0,00 & 0,25 & 0,50 & 1,00 \\
\hline Milho & $91,5 \mathrm{Aa}$ & $95,0 \mathrm{Aa}$ & $86,0 \mathrm{Aa}$ & $86,0 \mathrm{Aa}$ \\
Milheto & $64,0 \mathrm{Ca}$ & $56,5 \mathrm{Ba}$ & $54,5 \mathrm{Ca}$ & $28,0 \mathrm{Cb}$ \\
Sorgo & $76,0 \mathrm{Ba}$ & $64,0 \mathrm{Bab}$ & $68,5 \mathrm{Bab}$ & $58,0 \mathrm{Bb}$ \\
\hline CV\% & & \multicolumn{3}{c}{9,73} \\
\hline
\end{tabular}

Apesar de o herbicida trifluralin pertencer a um grupo químico especialmente eficiente no controle de gramíneas oriundas de sementes, o milho apresentou-se como espécie cuja germinação não foi afetada significativamente pela presença da molécula, mesmo em maiores concentrações (Figura 1). O efeito desse herbicida não envolve, necessariamente, a inibição da germinação, mas certamente causa redução no desenvolvimento radicular, ${ }^{11}$ como observado no presente trabalho.

${ }^{\ddagger}$ Médias seguidas de mesmas letras maiúsculas na coluna e minúscula na linha não diferem entre si pelo teste de Tukey a $5 \%$ de probabilidade. 


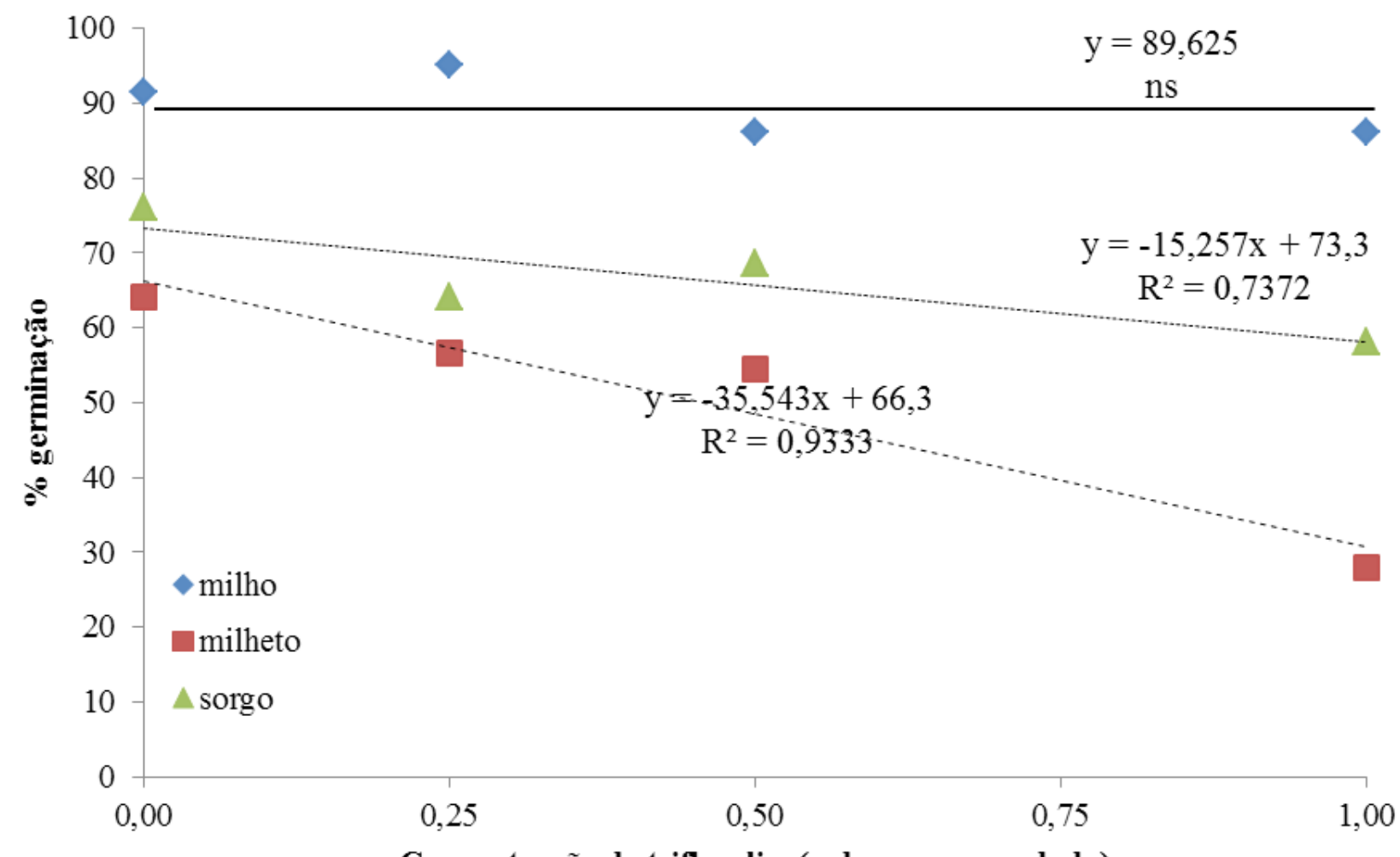

Figura 1 - Porcentagem de germinação de milho, milheto e sorgo em razão do substrato umedecido com concentrações crescentes de trifluralin $\left(3,0 \mathrm{~L} \mathrm{ha}^{-1}\right)$

As demais espécies apresentaram redução significativa à medida que a concentração era aumentada. Em sementes de sorgo, a redução foi de $23 \%$ entre a testemunha e a maior concentração, e no milheto, atingiu 56\%. Ambas as culturas responderam negativamente à presença do herbicida que umedecia o substrato, sendo o milheto a cultura mais sensível. São relatados efeitos inibitórios do trifluralin sobre plantas sensíveis causando paralização da mitose na prometáfase, pela interferência na polimerização da tubulina e na formação dos microtúbulos. ${ }^{12}$ Em nível de divisão celular, o herbicida pode alterar o padrão normal da mitose e causar anormalidades mitóticas, como metáfases desorganizadas; também, células poliploides e micronúcleos podem ser observados. ${ }^{3}$

Dessa maneira, para aferir melhor o efeito do herbicida nas três culturas testadas, foram avaliados outros parâmetros, como IVG, comprimento de plântula e massa seca, sendo esses resultados considerados para a verificação do efeito dos processos metabólicos que interferiram no desenvolvimento inicial das plantas. 
Os resultados quanto à velocidade de germinação estão demonstrados na Tabela 3. Verifica-se que para sementes de milho a velocidade de germinação foi sempre maior que as demais espécies, para todas as doses testadas. Entretanto, para essa variável, nas duas maiores concentrações, houve redução no IVG do milho, demonstrando que, mesmo não havendo diferença na germinabilidade das sementes, o herbicida provocou atraso germinativo, culminando em redução de $15 \%$ na velocidade do processo (Figura 2).

Tabela 3 - Índice de Velocidade de Germinação (IVG) das sementes de milho, milheto e sorgo submetidas a substrato contaminado com concentrações crescentes de trifluralin $\left(3,0 \mathrm{~L} \mathrm{ha}^{-1}\right)^{\varsigma}$

\begin{tabular}{ccccc}
\hline \multirow{2}{*}{ Espécies } & \multicolumn{4}{c}{ Concentração de trifluralin (x dose recomendada) } \\
\cline { 2 - 5 } & 0,00 & 0,25 & 0,50 & 1,00 \\
\hline Milho & $11,08 \mathrm{Aa}$ & $11,26 \mathrm{Aa}$ & $10,04 \mathrm{Ab}$ & $10,01 \mathrm{Ab}$ \\
Milheto & $7,83 \mathrm{Ca}$ & $5,99 \mathrm{Bb}$ & $4,96 \mathrm{Cb}$ & $2,13 \mathrm{Cc}$ \\
Sorgo & $8,89 \mathrm{Ba}$ & $7,03 \mathrm{Bbc}$ & $7,51 \mathrm{Bb}$ & $6,00 \mathrm{Bc}$ \\
\hline CV \% & \multicolumn{3}{c}{7,78} \\
\hline
\end{tabular}

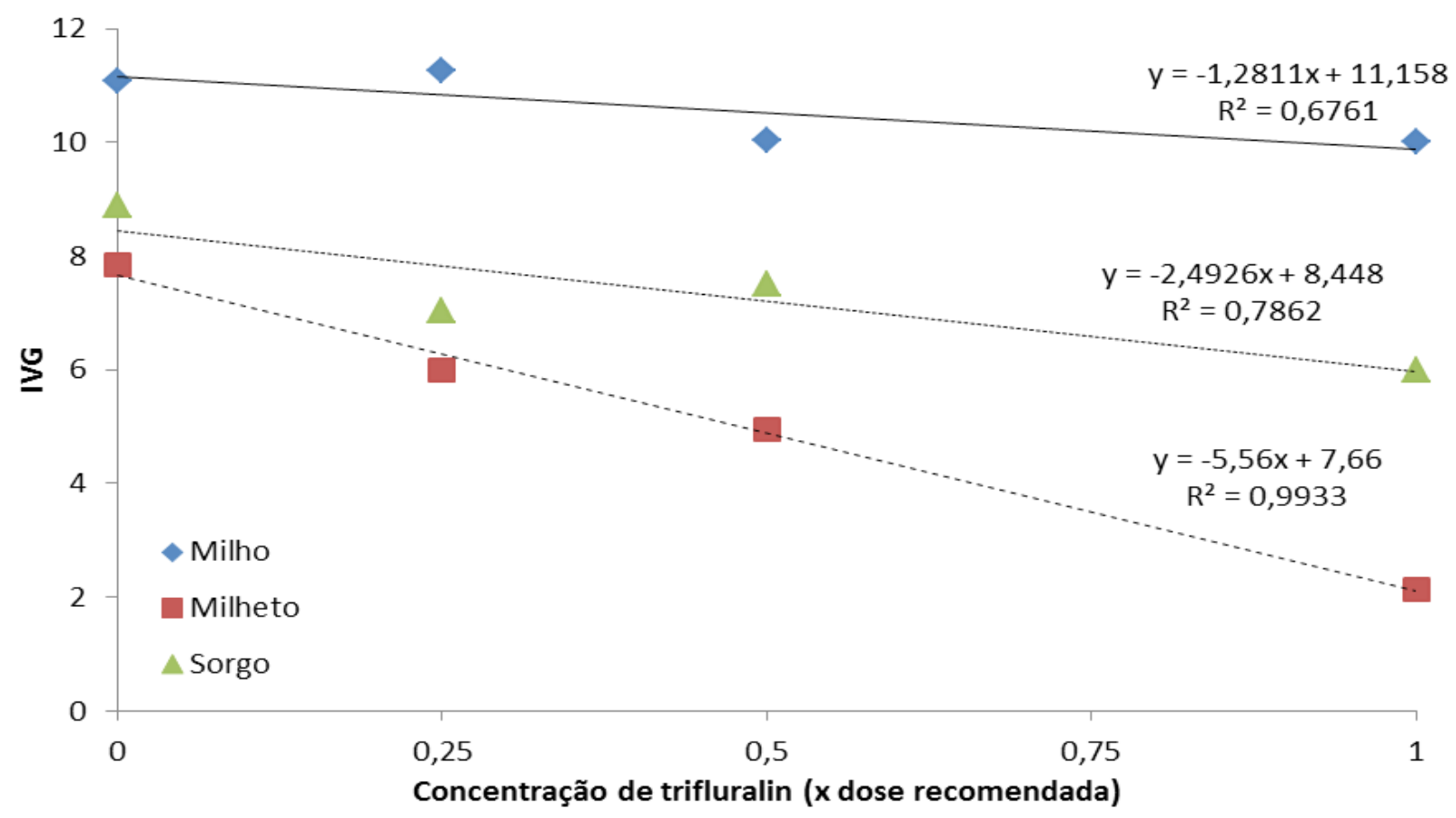

Figura 2 - Índice de Velocidade de Germinação (IVG) de sementes de milho, milheto e sorgo em decorrência do substrato umedecido com concentrações crescentes de trifluralin $\left(3,0 \mathrm{~L} \mathrm{ha}^{-1}\right)$

Sementes de milheto foram as que necessitaram de mais tempo para que a germinação ocorresse, quando comparadas às outras duas espécies. Essas sementes apresentaram decréscimo linear,

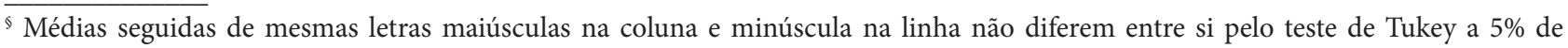
probabilidade.
} 
chegando a ser 32\% menores que a testemunha. Espécies sensíveis, como foi o caso do milheto e principalmente do sorgo, tendem a apresentar sintomas de intoxicação com o herbicida, dependendo da concentração. Esse sintoma pode ser a baixa germinabilidade, mas, também, a velocidade do processo, como observado na Tabela 3.

Quanto ao comprimento de raiz, os dados encontram-se na Tabela 4. Verifica-se que para as sementes de milho houve uma redução que variou entre 86 e $88 \%$ no comprimento da raiz entre as dosagens testadas, não havendo diferença entre elas. Essa redução foi observada também nas demais espécies, cuja variação foi de 86 a 97\% e de 74 a 78\% para milheto e sorgo, respectivamente.

O efeito do trifluralin causou forte inibição do crescimento radicular, resultando em características como entumescimento das extremidades das raízes, também relatadas por outros autores. ${ }^{13,14}$ Esse entumescimento, sob o aspecto morfológico, está associado à redução ou paralisação da divisão celular, embora a expansão radial das células se mantenha. ${ }^{15,11,16}$ Resíduos de trifluralin acumulados ao longo de várias aplicações podem reduzir o sistema radicular do sorgo e, consequentemente, a sua produtividade. $^{2}$

Tabela 4 - Comprimento da raiz principal das sementes de milho, milheto e sorgo submetidas a substrato contaminado com concentrações crescentes de trifluralin $\left(3,0 \mathrm{~L} \mathrm{ha}^{-1}\right)^{\|}$

\begin{tabular}{ccccc}
\hline \multirow{2}{*}{ Espécies } & \multicolumn{4}{c}{ Concentração de trifluralin (x dose recomendada) } \\
\cline { 2 - 5 } & 0,00 & 0,25 & 0,50 & 1,00 \\
\hline Milho & $100 \mathrm{Aa}$ & $12,85 \mathrm{Bb}$ & $12,69 \mathrm{Bb}$ & $13,94 \mathrm{Abb}$ \\
Milheto & $100 \mathrm{Aa}$ & $12,73 \mathrm{Bb}$ & $11,69 \mathrm{Bb}$ & $3,54 \mathrm{Bb}$ \\
Sorgo & $100 \mathrm{Aa}$ & $26,76 \mathrm{Ab}$ & $27,18 \mathrm{Ab}$ & $22,37 \mathrm{Ab}$ \\
\hline $\mathrm{CV} \%$ & \multicolumn{3}{c}{16,77} \\
\hline
\end{tabular}

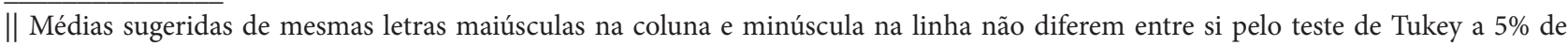
probabilidade. 


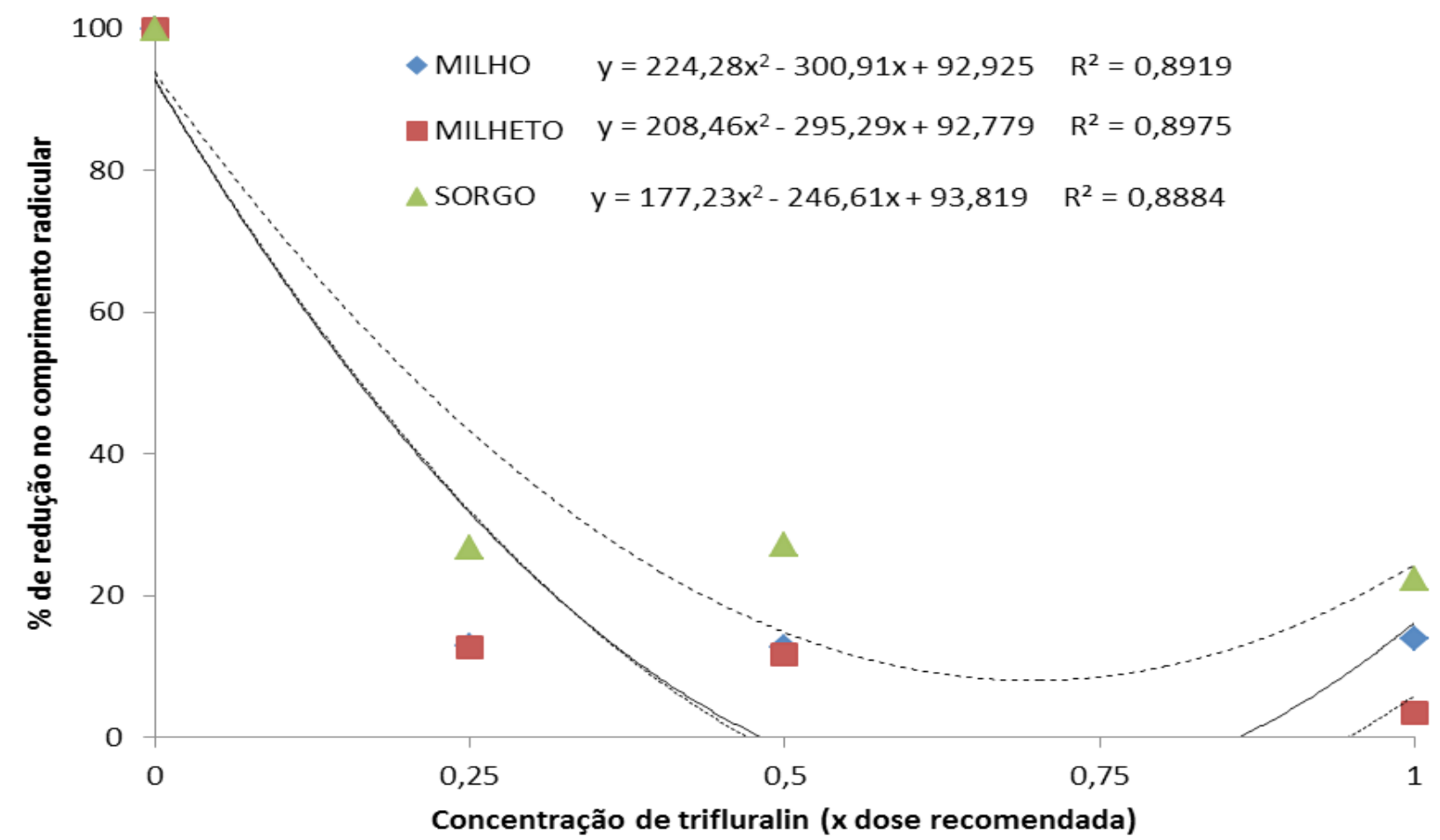

Figura 3 - Porcentagem de redução no comprimento radicular de plântulas de milho, milheto e sorgo em razão do substrato umedecido com concentrações crescentes de trifluralin $\left(3,0 \mathrm{~L} \mathrm{ha}^{-1}\right)$

Para a variável massa seca, à medida que se aumentava a dose do herbicida ocorria um aumento no peso das plântulas (Tabela 4), seguindo uma regressão quadrática, conforme apresentado na Figura 3.

Com $0,50 \%$ da concentração do herbicida, verificou-se um aumento de $17,3 \%$ em relação à testemunha. Mas na maior dose testada, houve um decréscimo de 8,7\% em relação à dose anterior. Os herbicidas do grupo químico das dinitroanilinas inibem a divisão celular, e a aplicação incorreta resulta na malformação de raízes, especialmente as secundárias. ${ }^{11,6}$ Os sintomas de fitointoxicação se manifestam por meio da formação de raízes curtas, grossas e com a aparência de terem sido podadas. Essa alteração fisiológica pode comprometer a translocação normal de substâncias sintetizadas para as regiões de crescimento da plântula, havendo acúmulo exagerado, sem seu gasto e conversão em desenvolvimento vegetal. ${ }^{13}$ Dessa maneira, esse aumento da massa vegetal, mesmo em plântulas malformadas pode ser indicativo de alterações fisiológicas que prejudicarão a planta adulta e, consequentemente, a sua capacidade produtiva.

Na variável massa seca, houve redução acentuada na produção de massa seca nas doses de 0,27 e $0,54 \mathrm{~kg} \mathrm{ha}^{-1}$, a qual se estabilizou a partir da dose de $1,08 \mathrm{~kg} \mathrm{ha}^{-1} .{ }^{1}$ Essa diferença foi observada apenas nas culturas do feijão e soja; para milho não foi observada essa diferença. 
Tabela 5 - Massa seca e comprimento da parte aérea de plântulas de milho, milheto e sorgo em razão do substrato umedecido com concentrações crescentes de trifluralin $\left(3,0 \mathrm{~L} \mathrm{ha}^{-1}\right)^{9}$

\begin{tabular}{ccc}
\hline \multirow{2}{*}{$\begin{array}{c}\text { Concentração de trifluralin }(\mathbf{x} \\
\text { dose recomendada) }\end{array}$} & \multicolumn{2}{c}{ Variáveis } \\
\cline { 2 - 3 } & Massa seca & Comprimento da parte aérea \\
\hline 0,00 & $100,0 \mathrm{~B}$ & $100,00 \mathrm{~A}$ \\
0,25 & $104,7 \mathrm{AB}$ & $14,43 \mathrm{~B}$ \\
0,50 & $117,3 \mathrm{~A}$ & $12,80 \mathrm{~B}$ \\
1,00 & $108,6 \mathrm{AB}$ & $9,27 \mathrm{~B}$ \\
\hline $\mathrm{CV}(\%)$ & 12,44 & 22,97 \\
\hline
\end{tabular}

O comprimento da parte aérea seguiu a tendência de decréscimo observada no IVG e principalmente no sistema radicular. Entretanto, as espécies não diferiram entre si, seguindo uma redução quadrática, baseada na equação $y=231,17 x^{2}-294,74 x+93,125\left(r^{2}=0,9004\right)$ (Figura 3). Dependendo do grau de fitointoxicação, também ocorre engrossamento do hipocótilo. Além disso, poderá ocorrer atrofia da parte aérea da planta. As folhas podem se apresentar menores, enrugadas e com coloração verde-escura. ${ }^{15}$ Essas características foram verificadas em todas as plântulas estudadas, especialmente a intensa coloração verde nas maiores concentrações.

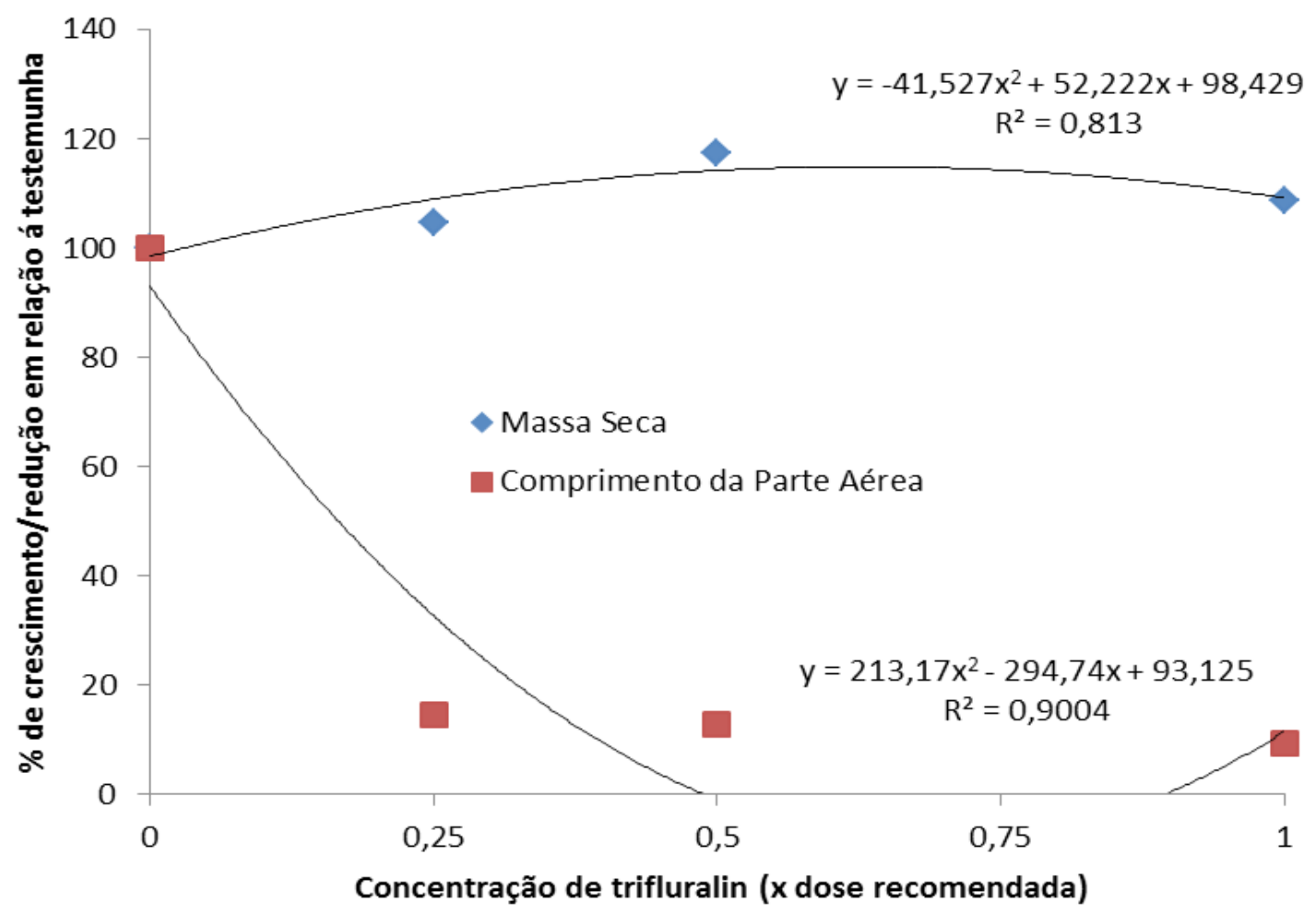

Figura 3 - Porcentagem de redução no comprimento radicular de plântulas de milho, milheto e sorgo em razão do substrato umedecido com concentrações crescentes de trifluralin $\left(3,0 \mathrm{~L} \mathrm{ha}^{-1}\right)$

'Médias seguidas de mesmas letras maiúsculas na coluna e minúscula na linha não diferem entre si pelo teste de Tukey a $5 \%$ de probabilidade. 


\section{CONCLUSÃO}

Os resultados sobre a germinação e crescimento de plântulas das culturas de milho, milheto e sorgo em substrato umedecido com o herbicida trifluralin permitem concluir que o milho (Zea mays L.) é a espécie mais tolerante aos efeitos do herbicida nas concentrações estudadas; o herbicida, mesmo em sua menor concentração, causou fitointoxicação com efeito negativo na germinação e no desenvolvimento inicial de milheto e sorgo, principalmente, no desenvolvimento radicular; e o milheto foi à cultura mais sensível aos efeitos do trifluralin.

\section{REFERÊNCIAS}

1. Santos G, Francischini AC, Constantin J, Oliveira JRRS. Carryover proporcionado pelos herbicidas s-metolachlor e trifluralin nas culturas de feijão, milho e soja. Planta Daninha. 2012; 30(4):827-34.

2. Empresa Brasileira de Pesquisa Agropecuária. Sistema de Produção Sorgo. [Internet]. [acesso em 2015 mar 18]. Disponível em: http://www.cnpms.embrapa.br/publicacoes/sorgo 8 ed/index.htm

3. Oliveira VR, Scapim CA, Oliveira JRRS, Pires NM. Efeito do herbicida trifluralin sobre a germinação de sementes e o índice mitótico em raízes de milho (Zea mays L.). Revista Unimar. 1996; 18(4):537-44.

4. Gomez BD, Gamon M, Lorenzo E, Saez A. Residual herbicide movement in soil columns. Science of The Total Environment. 1993; 132(2):155-65.

Gerwing PD, Mckercher RB. The relative persistence of trifluralin (S 45 EC and 5 G) and ethalfluralin in prairie soils. Canadian Journal of Soil Science. 1993; 72(3):255-62.

5. Rodrigues BN, Almeida FS. Guia de Herbicidas. 6. ed. Londrina: IAPAR; 2011.

6. Oliveira P, Nascente AS, Kluthcouski J, Portes TA. Crescimento e produtividade de milho em função da cultura antecessora. Pesquisa Agropecuária Tropical. 2013; 43(3):239-46.

7. Vargas L, Peixoto CM, Roman ES. Manejo das plantas daninhas na cultura de milho. [Internet]. Passo Fundo: Embrapa Trigo; 2006. [acesso em 2015 set 09]. Disponível em: http://www.cnpt. embrapa.br/biblio/do/p do61.pdf

8. Brasil. Ministério da Agricultura, Pecuária e Abastecimento. Regras para Análise de Sementes. Secretaria de Defesa Agropecuária. Brasília, DF: Mapa/ACS; 2009.

9. Ferreira DF. Sisvar: a computer statistical analysis system. Ciência e Agrotecnologia. 2011; 35(6):1039-42. 
10. Hartzler RG, Fawcett RS, Taber HG. Efects of trifluralin on corn (Zea mays) growth and nutrient content. Weed Science. 1990; 38(3):468-70.

11. Hess D, Bayer DE. Binding of the herbicide trifluralin to Chlamydamonas flagellar tubulin. Journal of Cell Science. 1977; 24(3):351-60.

12. Lignowski EM, Scott EG. Effect of trifluralin on mitosis. Weed Science. 1972; 20(2):267-70.

13. Yamashita OM, Borges RH, Carvalho MAC. Efeito de três herbicidas na germinação de corda-deviola (Ipomoea quamoclit) em substrato umedecido. Revista Científica Eletrônica de Agronomia. 2010; 17(1):17-22.

14. Brighenti AM, Adegas FS, Bortoluzi ES, Almeida LA, Voll E. Tolerância de genótipos de soja aos herbicidas trifluralin e imazaquin. Planta Daninha. 2002; 20(1):63-9.

15. Varela R, Cruz R. Effecto de algunas dinitroanilinas sobre la nodulacion de la soya (Glycine max (L,) Merr.). Revista do Instituto Colombiano de Agropecuária. 1984; 19(1):17-23. 